\title{
Welke tumoren worden gemist wanneer systematische biopten achterwege gelaten worden bij patiënten met de verdenking op prostaatcarcinoom? ('DROPP-IT')
}

\author{
Roderick C. N. van den Bergh · Daan J. Reesink · Lieke Wever · Timo F. W. Soeterik · Sandrine van Selm • \\ Pascal E. F. Stijns · Erik J. R. J. van der Hoeven - Peter C. de Bruin - Harm H. E. van Melick
}

Geaccepteerd op: 9 augustus 2021 / Published online: 22 september 2021

(C) The Author(s) 2021

\begin{abstract}
Samenvatting De MRI-scan van de prostaat heeft de bioptstrategie sterk beïnvloed. Toch kunnen bij een normale MRI biopten geïndiceerd blijven: zowel gerichte als systematische. In deze studie werd geanalyseerd welke prostaattumoren gemist zouden worden in de hypothetische situatie dat er geen systematische biopten genomen waren in ons cohort, en dat de MRI volledig leidend zou zijn geweest in het diagnostisch pad. Als referentie dienden de uitkomsten van het standaardprotocol, waarin alle verwezen patiënten $(n=496)$ een MRI krijgen, er bij een verhoogde kans op prostaatkanker volgens de ERSPCprostaatwijzer óf afwijkende MRI biopten worden genomen, en er altijd systematische, plusgerichte biopten worden verricht, indien mogelijk. Uit de analyse bleek dat $16 \%$ van de tumoren met een ISUPgraad $\geq 2(\geq 3+4=7)$ gemist zou zijn, maar ook dat slechts $66 \%$ van de patiënten gebiopteerd zou hoeven worden, met $50-75 \%$ minder cores, en dat $52 \%$ van de ISUP-gr $1(3+3=6)$-tumoren ongedetecteerd zouden blijven.
\end{abstract}

Trefwoorden bioptstrategie - prostaatcarcinoom . ERSPC-prostaatwijzer · MRI · Gleason-score

dr. R. C. N. van den Bergh $(\bowtie) \cdot$ drs. D. J. Reesink .

drs. L. Wever · drs. T. F. W. Soeterik · drs. S. van Selm .

drs. P. E. F. Stijns · dr. H. H. E. van Melick

afdeling Urologie, St. Antonius Ziekenhuis,

Utrecht/Nieuwegein/Woerden, Nederland

r.van.den.bergh@antoniusziekenhuis.nl

dr. E. J. R. J. van der Hoeven

afdeling Radiologie, St. Antonius Ziekenhuis,

Utrecht/Nieuwegein/Woerden, Nederland

dr. P. C. de Bruin

afdeling Pathologie, St. Antonius Ziekenhuis,

Utrecht/Nieuwegein/Woerden, Nederland
Which tumors are missed if systematic biopsies are omitted in patients with a suspicion of prostate cancer? ('DROPP-IT')

Abstract MRI of the prostate has dramatically changed and improved the biopsy indication and biopsy strategy. Still, even with a normal MRI an indication for biopsy may exist. Also, systematic biopsies are recommended in addition to targeted cores. This article presents which prostate tumors would have been missed in the hypothetical situation that no systematic biopsies would have been performed in our cohort, with a fully MRI dependent diagnostic strategy. As a reference the results of the standard pathway were used, in which all patients $(n=496)$ underwent MRI, but a risk indicator could also independently indicate biopsy, and targeted plus systematic biopsies were always performed, if possible. In total, $16 \%$ of ISUP gr $\geq 2$ (Gleason $\geq 3+4=7$ ) tumors would have been missed, but only $66 \%$ would have been biopsied, with $50-75 \%$ less cores, and $52 \%$ ISUP gr $1(3+3=6)$ tumors would have remained undetected.

Keywords MRI · biopsystrategy · Gleason-score · risk calculator $\cdot$ prostate cancer

\section{Introductie}

Het optimale diagnostisch traject bij de verdenking op prostaatkanker detecteert alle significante tumoren en geen niet-significante afwijkingen, met een zo laag mogelijke belasting voor de patiënt en natuurlijk met zo gering mogelijke kosten. De MRI van de prostaat heeft het traject ingrijpend veranderd en zowel de indicatiestelling voor het nemen van prostaatbiopten als de bioptstrategie zelf positief beïnvloed [1].

Door niet te biopteren bij een vast PSA-afkappunt, maar alleen bij een afwijkende MRI, wordt ruw- 
weg $25 \%$ minder mannen gebiopteerd [2]. De MRI mist echter ongeveer $10 \%$ van de Gleason $\geq 3+4=7$ tumoren [3]. Een risicocalculator, zoals de ERSPCprostaatwijzer, verbetert de selectie van patiënten die in aanmerking komen voor prostaatbiopten ook [4]. MRI en prostaatwijzer worden in Nederland vaak gecombineerd of achtereenvolgens gebruikt om vast te stellen of er een indicatie is voor biopten. Welke diagnosticum wordt gekozen - MRI en/of prostaatwijzer - en de volgorde waarin deze worden ingezet, beïnvloeden het aantal bioptindicaties en het aantal significante en niet-significante tumoren dat wordt gevonden [5]. Is er een indicatie voor een prostaatbiopt, dan luidt het advies om voorafgaand aan ieder biopt een MRI van de prostaat te verrichten [1]. Vervolgens kunnen de biopten systematisch, gericht of gecombineerd worden afgenomen. Gerichte biopten detecteren $18 \%$ meer significante prostaatkanker dan systematische biopten [6]. Het achterwege laten van systematische biopten kan $10-15 \%$ van de significante tumoren missen vergeleken met de combinatie van systematische en gerichte biopten [7, 8]. Gecombineerde biopten geven ook een betere inschatting van prostatectomie-uitkomsten, alhoewel dit verschil beperkt is en met name wordt veroorzaakt door Gleason 3+4-tumoren [8]. Bij MRI PI-RADS 5-laesies is de toegevoegde waarde van systematische biopten relatief het kleinst [9].

De Nederlandse 4M-studie presenteerde de resultaten van een gecombineerd diagnostisch pad, waarbij alleen bij een afwijkende MRI gerichte biopten werden genomen. Door het achterwege laten van systematische biopten bij een negatieve MRI werd $4 \%$ van de significante tumoren gemist. Vervolgens werd met de gerichte biopten een vergelijkbaar aantal significante tumoren gevonden, terwijl het aantal niet-significante tumoren sterk daalde [10].

In dit artikel presenteren we de resultaten van een cohort patiënten met de verdenking op prostaatcarcinoom, bij wie een MRI-geleid diagnostisch pad met alleen gerichte biopten werd gehanteerd. De uitkomsten van dit hypothetische pad werden vergeleken met het door ons toegepaste uitgebreidere referentiepad, waarin bij alle patiënten een MRI werd verricht, maar ook de prostaatwijzer werd gebruikt om tot biopten over te gaan, en er altijd gerichte plus systematische biopten werden genomen.

\section{Materiaal}

\section{Patiënten}

Het studiecohort omvat alle mannen die via de huisarts werden verwezen naar het St. Antonius Ziekenhuis Utrecht/Nieuwegein/Woerden tussen augustus 2018 en april 2019 vanwege verdenking op prostaatcarcinoom op basis van een verhoogd PSA en/of afwijkend rectaal toucher. Over het algemeen werd vanuit de huisarts de PSA-afkapwaarde van $3,0 \mathrm{ng} / \mathrm{ml}$ gehanteerd. Exclusiecriteria voor de studie waren eerdere prostaatbiopten of een MRI van de prostaat, contra-indicaties voor een MRI, of het gebruik van finasteride of dutasteride. Patiënten met een hoge kans op gemetastaseerde ziekte (PSA > 50 ng/ml) werden in principe niet geïncludeerd.

De studie werd goedgekeurd door de medisch-ethische commissie MECU van het St. Antonius Ziekenhuis (W17.087) en werd uitgevoerd volgens 'good clinical practice' guidelines.

\section{Protocol}

Alle patiënten ondergingen een MRI van de prostaat en voor alle patiënten werd de ERSPC-prostaatwijzer ingevuld om de kans op een positief prostaatbiopt te berekenen [4]. Het protocol adviseerde prostaatbiopten bij een uitkomst op de prostaatwijzer van $\geq 20 \%$ óf een afwijkende MRI (PI-RADS 3-4-5), en wanneer beide daartoe aanleiding gaven. Er was alleen geen indicatie voor biopten bij patiënten met een lage uitkomst op de prostaatwijzer én een niet-afwijkende MRI.

\section{Biopt}

Bij een indicatie voor een biopt adviseerde het protocol afname van zowel gerichte (minimaal 2 biopten van iedere MRI-laesie) als systematische biopten (8, 10 of 12 afhankelijk van het prostaatvolume van resp. $<40,40-60$ of $>60 \mathrm{ml}$ ). Richten van de biopten vond plaats via cognitieve fusie [11]. Systematische biopten werden gelateraliseerd en verdeeld over basis tot apex van de perifere zone. In deze periode werden in ons ziekenhuis prostaatbiopten standaard transrectaal afgenomen door ervaren urologen (> 1.000 biopten) met een 'biplane' TRUS-probe (Hitachi, diverse systemen). De biopten werden geanalyseerd door ervaren pathologen met aandachtsgebied uropathologie volgens de ISUP 2014-protocollen [12]. Voor deze studie werd significant prostaatcarcinoom gedefinieerd als Gleason $\geq 3+4=7$ (ISUP Grade Group $\geq 2$ ) in minimaal één prostaatbiopt.

\section{De ERPSC-prostaatwijzer}

Het risico op een positief biopt werd berekend met behulp van wijzer 3 van de ERPSC-prostaatwijzer [13]. Deze calculator voorspelt het risico op het vinden van prostaatkanker met systematische prostaatbiopten en het risico op hooggradige prostaatkanker op basis van PSA, rectaal toucher, volume en TRUS-resultaten. Voor het bepalen van het prostaatvolume werd de MRI gebruikt. De MRI-PI-RADS-resultaten werden niet meegenomen in de prostaatwijzerberekeningen. Ook werd de voorspelling voor hooggradige prostaatkanker uit de prostaatwijzer niet in overweging genomen. 


\section{MRI-scan}

Er werd een biparametrisch MRI-protocol gescand op een 3 Tesla-scanner met een pelvic-phased array coil. Verdere details zijn opvraagbaar bij de auteur (EvdH). De beelden werden gescoord naar aanleiding van PIRADS (Prostate Imaging Reporting and Data System) versie 2 [14]. Aangezien de Dynamic Contrast Enhanced (DCE) serie ontbrak, konden bij een afwijkend DCE, de PI-RADS 3-laesies die in de perifere zone waren gelegen niet geüpgraded worden. De beelden werden door ervaren uro-radiologen (> 1.000 scans) beoordeeld en meestal werd double-reading toegepast in het radiologieoverleg. Iedere patiënt met een PIRADS-score 3-4-5 werd besproken in een multidisciplinair overleg, om te bepalen of er een indicatie was voor een biopsie en om de strategie vast te stellen.

\section{Analyse}

Als referentie werden de uitkomsten van ons standaard diagnostisch pad gebruikt. In dit pad kreeg iedereen een MRI, was er een ruime bioptindicatie (prostaatwijzer en/of MRI) en, indien mogelijk, werden altijd gerichte plus systematische biopten verricht. Binnen deze uitgebreide bioptindicatie en -strategie werd een hypothetisch beperkter diagnostisch pad geanalyseerd, waarbij werd beoordeeld wat de uitkomsten waren geweest als:

1. de bioptindicatie alleen was gesteld op basis van de MRI, dus wanneer systematische biopten bij een normale MRI achterwege waren gelaten;

2. er bij een bioptindicatie op basis van de MRI alleen gerichte biopten en geen systematische biopten waren genomen.

Uitkomsten betroffen het aantal bioptindicaties, het aantal bioptcores en het aantal significante en nietsignificante tumoren van de patiënten die het referentiepad volgden in vergelijking met de patiënten die het MRI-gerichte pad volgden. Als bij een patiënt het protocol voor bioptindicatie niet was gevolgd, werden de gegevens van die patiënt geëxtrapoleerd op basis van de resultaten van patiënten in dezelfde groep die wél biopten hadden ondergaan. Er werd voor deze studie geen formele powerberekening verricht en er werden geen statistische tests uitgevoerd.

\section{Resultaten}

Er werden in totaal 496 patiënten geïncludeerd in het cohort. Figuur 1 toont de studieopzet en de uitkomsten. In tab. 1 staan de belangrijkste patiëntkarakteristieken van deze groep. Bij 306 patiënten (62\%) werd

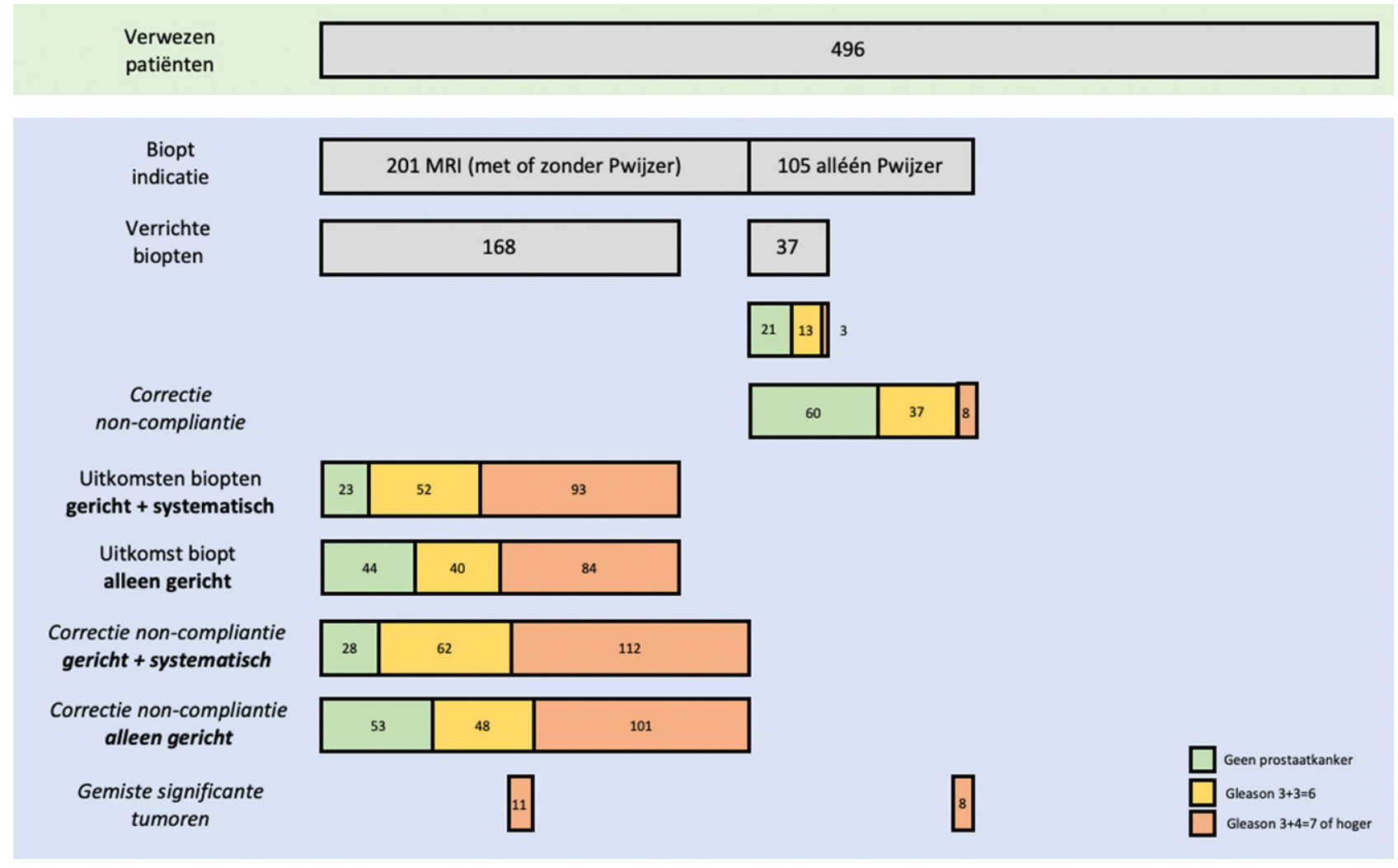

Figuur 1 Studieopzet en uitkomsten. Geëxtrapoleerd naar $100 \%$ bioptcompliantie zouden er $120(8+112)$ significante tumoren gevonden worden. Met achterwege laten van systematische biopten bij een normale MRI, maar bij prostaat
(Pr) wijzer $\geq 20 \%$, zou $7 \%(8 / 120)$ van de significante tumoren gemist worden. Met achterwege laten van systematische biopten bij een afwijkende MRI (alleen gerichte biopten nemen) zou $9 \%(11 / 120)$ van de significante tumoren gemist worden 
een indicatie gesteld voor biopten: bij 141 (28\%) patiënten op basis van een prostaatwijzerscore $\geq 20 \%$ én de MRI PI-RADS 3-4-5, bij 60 (12\%) patiënten op basis van enkel een MRI PI-RADS 3-4-5, en bij 105 (22\%) patiënten enkel op basis van prostaatwijzer.

Bij de groep met een indicatie voor een biopt ( $n=306)$ werden $205(67 \%)$ biopten verricht. De bioptcompliantie was $87 \%(125 / 141)$ bij mannen die op basis van een prostaatwijzerscore $\geq 20 \%$ én een afwijkende MRI een indicatie voor een biopt hadden, $72 \%(43 / 60)$ bij de mannen die een indicatie hadden enkel op basis van een MRI PI-RADS 3-4-5 en 35\% bij patiënten die een indicatie hadden op basis van enkel een prostaatwijzerscore $\geq 20 \%$. De compliantie voor de bioptindicatie was hoger bij mannen met een hogere score op de prostaatwijzer en een hogere PI-RADS-score. Bij 96 patiënten werd significante en bij 44 patiënten niet-significante prostaatkanker gevonden (omgerekend naar $100 \%$ bioptcompliantie zouden dit resp. 120 en 88 patiënten geweest zijn).

\section{Achterwege laten van systematische biopten bij normale MRI maar een prostaatwijzerscore $\geq 20 \%$}

Wanneer de indicatie voor biopten alleen gesteld zou zijn op basis van een afwijkende MRI, en dus niet enkel op basis van een afwijkende score op de prostaatwijzer, zou er geen indicatie zijn geweest voor een biopt bij $34 \%$ (105/306) van de patiënten. Dan zou bij drie patiënten in dit cohort een significante tumor zijn gemist, alle ISUP-graad 2 (Gleason 3+4=7). Deze patiënten hadden een score op de prostaatwijzer van 26 , 40 en $43 \%$; één patiënt had een afwijkend rectaal toucher. Geëxtrapoleerd naar een $100 \%$ bioptcompliantie zouden acht significante tumoren zijn gemist, ofwel $7 \%(8 / 120)$ van het totaal en $37 \%(37 / 99)$ van het totaal aantal ISUP grade 1 (Gleason $3+3=6$ )-tumoren.

\begin{tabular}{l|c|l|l}
\multicolumn{3}{l}{ Tabel 1 Patiëntkarakteristieken referentiecohort $(n=496)$} \\
\hline karakteristieken & mediaan & IQR \\
\hline - leeftijd (jr) & 68 & $62-73$ \\
\hline - PSA (ng/ml) & 6,5 & $5,1-9,3$ \\
\hline - prostaatvolume (ml) & 50 & $35-70$ \\
\hline rectaal toucher & $n$ & $\%$ \\
\hline - normaal & 342 & 69 \\
\hline - afwijkend & 85 & 17 \\
\hline - niet bekend & 69 & 14 \\
\hline categorie prostaatwijzer & & \\
\hline$-<12,5 \%$ & 153 & 31 \\
\hline$-12,5-20 \%$ & 110 & 22 \\
\hline ->20\% & 233 & 47 \\
\hline PI-RADS & & \\
\hline-1 & 32 & 7 \\
\hline-2 & 263 & 53 \\
\hline-3 & 33 & 7 \\
\hline-4 & 78 & 16 \\
\hline-5 & 90 & 18 \\
\hline
\end{tabular}

\section{Achterwege laten van systematische biopten bij} afwijkende MRI

Wanneer er bij patiënten met een afwijkende MRI enkel gerichte biopten zouden zijn genomen in plaats van gerichte plus systematische biopten, zou het aantal bioptcores met ongeveer driekwart zijn verminderd (2-3 per patiënt versus mediaan 10). Binnen deze groep zouden in dit cohort dan negen significante tumoren zijn gemist, waarvan zes met ISUPgraad 2 (Gleason 3+4=7) en drie ISUP-graad 4 (Gleason $4+4=8$ ). In tab. 2 staan de patiëntkarakteristieken van deze negen patiënten. Twee patiënten hadden een afwijkend rectaal toucher én een PSA > 10 én PI-RADS 5. Bij zes van de negen (67\%) patiënten bij wie de systematische biopten iets toevoegden aan de gerichte biopten, betrof dit dezelfde zijde als (een van) de MRI-laesie(s). Geëxtrapoleerd naar een bioptcompliantie van $100 \%$ zouden 11 significante tumoren zijn gemist, ofwel $9 \%(11 / 120)$ van het totaal, en $23 \%(14 / 62)$ van het totaal aantal ISUP-graad 1tumoren (Gleason $3+3=6$ ).

Bij het volledig achterwege laten van systematische biopten zou in totaal $16 \%(19 / 120)$ van de significante tumoren en $52 \%(51 / 99)$ van de niet-significante tumoren zijn gemist.

\section{Discussie}

In deze studie presenteerden we de uitkomsten van een hypothetisch diagnostisch pad voor prostaatkanker wanneer systematische biopten achterwege gelaten zouden worden, dus met een bioptindicatie die volledig is gebaseerd op MRI en met alleen gerichte biopten. Deze uitkomsten hebben we vergeleken met het referentiepad zoals daadwerkelijk is toegepast in ons ziekenhuis, waarin ook de prostaatwijzer werd gebruikt als bioptindicatie, en met de combinatie van gerichte en systematische biopten.

Door de systematische biopten achterwege te laten bij mannen met een afwijkende score op de prostaatwijzer maar een normale MRI, zou de bioptindicatie bij één op de drie patiënten vervallen, maar zou $7 \%$ van de significante prostaatcarcinomen worden gemist. Door de systematische biopten achterwege te laten bij mannen met een afwijkende MRI en dus alleen gerichte biopten te nemen, zou er circa $75 \%$ minder bioptcores hoeven te worden afgenomen, maar zou $9 \%$ significant prostaatcarcinoom worden gemist. De gemiste carcinomen betroffen met name ISUP-graad 2-tumoren (Gleason $3+4=7$ ). Als gevolg van beide strategieën zouden ook veel minder $(52 \%)$ ISUP graad 1-tumoren (Gleason 3+3=6) gediagnosticeerd worden.

Onze bevindingen zijn in grote lijnen iets gunstiger dan in de literatuur is beschreven. Sathianathen et al. vonden in een review een gecombineerd negatief voorspellende waarde van de MRI van 90,8\% bij een Gleason-score $\geq 3+4=7$ [3]. Dat wil zeggen dat 
Tabel 2 Overzicht van patiëntkarakteristieken van de negen patiënten bij wie de systematische biopten ISUP-graad $\geq 2$ (Gleason $\geq 3+4=7$ ) hadden en de gerichte biopten geen maligniteit of ISUP-graad 1 (Gleason 3+3=6)

\begin{tabular}{|c|c|c|c|c|c|c|c|c|c|}
\hline & \multicolumn{9}{|c|}{ patiënt } \\
\hline & 1 & 2 & 3 & 4 & 5 & 6 & 7 & 8 & 9 \\
\hline leeftijd & 71 & 72 & 60 & 67 & 68 & 56 & 65 & 69 & 60 \\
\hline PSA & 10,1 & 10,6 & 11,1 & 4,5 & 4,2 & 5,6 & 5,2 & 29,7 & 5 \\
\hline volume & 30 & 55 & 56 & 46 & 55 & 32 & 50 & 48 & 12 \\
\hline digital rectal examination & cT2 & $\mathrm{Gb}$ & $\mathrm{Gb}$ & $\mathrm{Gb}$ & cT2 & $\mathrm{Gb}$ & $\mathrm{Gb}$ & cT2 & $\mathrm{Gb}$ \\
\hline prostaatwijzer & 71 & 28 & 29 & 12 & 16 & 27 & 13 & 86 & 65 \\
\hline PI-RADS & 5 & 5 & 4 & 5 & 4 & 4 & 4 & 5 & 4 \\
\hline TB & 2 & 3 & 2 & 2 & 3 & 3 & 3 & 2 & 3 \\
\hline TB positief & 2 & 3 & 0 & 0 & 2 & 3 & 0 & 2 & 2 \\
\hline SB links & 3 & 5 & 5 & 4 & 4 & 5 & 4 & 4 & 4 \\
\hline SB links positief & 3 & 3 & 3 & 4 & 2 & 1 & 0 & 0 & 0 \\
\hline SB rechts & 5 & 5 & 5 & 4 & 3 & 5 & 4 & 4 & 5 \\
\hline SB rechts positief & 4 & 2 & 0 & 3 & 3 & 4 & 2 & 4 & 3 \\
\hline
\end{tabular}

ongeveer $10 \%$ van de mannen met een normale MRI toch significant prostaatcarcinoom heeft. In ons cohort was dit $7 \%$. Ploussard et al. vonden dat een combinatie van systematische biopten en gerichte biopten ongeveer $10 \%$ meer significant prostaatcarcinoom vindt dan alleen gerichte biopten [7]. Dit percentage van $10 \%$ werd in ons cohort bevestigd.

De 4M-studie biedt ook een goede vergelijking, omdat deze studie een vergelijkbaar MRI-gericht diagnostisch pad bestudeerde [10]. In tab. 3 wordt een vergelijking gepresenteerd van het huidige cohort met de resultaten van de $4 \mathrm{M}$-studie. Deze vergelijking is met name 'hypothesegenererend'. Er zijn vele mogelijke oorzaken voor verschillen, zoals: prevalentie, kwaliteit van de MRI-beoordeling, kwaliteit en methode van gerichte en systematische biopten, patiëntselectie en prevalentie van prostaatcarcinoom, studieopzet, etc.

Het missen van significante tumoren is onwenselijk, maar kan worden genuanceerd:

- Misgeprikt. Van de door gerichte biopten gemiste significante tumoren lijken er enkele 'misgeprikt'. Ook is bij zes van de negen met door gerichte biopten gemist significant carcinoom, de tumor in de systematische biopten aan dezelfde zijde gevonden als de MRI-laesie. Groei op de leercurve of rondom de laesie afgenomen biopten zouden hiervoor kunnen corrigeren.

- Active surveillance. Bij een van de drie door gerichte biopten gemiste $4+4=8$-tumoren, is wel Gleason 6-prostaatcarcinoom gevonden in de gerichte biopten. Bij vijf van de zes gemiste $3+4=7$-tumoren is wel Gleason 6-prostaatcarcinoom gevonden in de gerichte biopten. Deze patiënten zouden waarschijnlijk in de strikte controles van een active-surveillanceschema terecht zijn gekomen.

- Controles. Mannen met een verhoogd PSA maar een normale MRI, worden over het algemeen gevolgd met PSA-controles, waarmee de afwijking op een later moment aan het licht zou zijn gekomen. Ook mannen met afwijkende MRI maar negatieve biopten (dit betrof 3 van de 9 gemiste, oftewel slechts 2-3\% van totaal aantal significante carcinomen dat werd gevonden) worden over het algemeen voor controles uitgenodigd. Bij hen kan mogelijk aanvullend een PSMA-PET/CT-scan worden verricht. De impact van een latere diagnose en behandeling is waarschijnlijk beperkt [15]. Tumoren met een intermediate risico die niet zichtbaar zijn op de MRI, zijn daarnaast kleiner en hebben een gunstiger uitkomst dan zichtbare tumoren [16].

Een diagnostisch pad dat leunt op beeldvorming voor bioptindicatie en biopten is een logische strategie; een afwijkende MRI geeft een grotere kans op significante prostaatkanker en biopten kunnen efficiënter worden ingezet door ze te richten op de laesie. Bij mannen die om een andere reden een bioptindicatie hebben, is de kans op significante kanker a priori al laag en bij hen kunnen alleen steekproefsgewijs biopten plaatsvinden. Door meer mannen te biopteren, met per definitie meer bioptcores, wordt meer kanker gevonden, maar de vraag is of deze 'winst' in balans is met de belasting (meer Gleason 6, ongemak, tijd, kosten, infecties [17], etc.). Daarbij kan adequate follow-up het initieel missen van deze significante tumoren ondervangen.

\section{Overwegingen en zwakke punten}

Er zijn veel overwegingen en zwakke punten te noemen bij deze studie.

1. Ook ons referentiepad is een relatieve uitkomst; theoretisch zouden de aantallen gevonden tumoren veranderen bij templatebiopten of prostatectomie 
Tabel 3 Vergelijking met de patiënten van het onderzochte cohort en het cohort van de 4M-studie [10]

\begin{tabular}{|c|c|c|}
\hline & huidig cohort & cohort 4M-studie \\
\hline \multicolumn{3}{|l|}{ patiënten } \\
\hline - aantal & 496 & 626 \\
\hline - gemiddelde leeftijd & 68 jaar & 65 jaar \\
\hline - gemiddeld PSA & $6,5 \mathrm{ng} / \mathrm{ml}$ & 6,4 \\
\hline - gemiddelde PSA-density & $0,13 \mathrm{ng} / \mathrm{ml}$ & $0,11 \mathrm{ng} / \mathrm{ml}$ \\
\hline - afwijkend rectaal toucher & $20 \%$ & $28 \%$ \\
\hline \multicolumn{3}{|l|}{ biopten } \\
\hline - bioptindicatie & $\begin{array}{l}\text { PrW } \geq 20 \% \text { en/of MRI PI- } \\
\text { RADS } 3-4-5\end{array}$ & $\begin{array}{l}\text { PSA } \geq 3,0 \text { en/of } \\
\text { MRI PI-RADS 3-4-5 }\end{array}$ \\
\hline - gerichte bioptstrategie & $\begin{array}{l}\text { cognitieve freehand, fusie } \\
2-3 \text { cores/laesie }\end{array}$ & $\begin{array}{l}\text { in-bore, } 2-4 \text { cores/ } \\
\text { laesie }\end{array}$ \\
\hline $\begin{array}{l}\text { - systematisch bioptstrate- } \\
\text { gie }\end{array}$ & $\begin{array}{l}\text { 8-10-12 afhankelijk } \\
\text { van prostaatvolume }\end{array}$ & 12 cores \\
\hline - bioptindicatie & $62 \%$ & $100 \%$ \\
\hline - significante PCa & $24 \%$ & $30 \%$ \\
\hline - niet-significante PCa & $18 \%$ & $23 \%$ \\
\hline \multicolumn{3}{|l|}{ MRI } \\
\hline - protocol & T2, DWI & T2, DWI, DCE \\
\hline - PI-RADS 1-2 & $59 \%$ & $49 \%$ \\
\hline - PI-RADS 3 & $7 \%$ & $6 \%$ \\
\hline - PI-RADS 4 & $16 \%$ & $22 \%$ \\
\hline - PI-RADS 5 & $18 \%$ & $23 \%$ \\
\hline \multicolumn{3}{|c|}{ weglaten systematische biopten ${ }^{b}$} \\
\hline $\begin{array}{l}\text { - significante PCa gemist } \\
\text { bij negatieve MRI }\end{array}$ & $7 \%\left(8 / 120^{a}\right)$ & $5 \%(10 / 200)$ \\
\hline $\begin{array}{l}\text { - significante PCa gemist } \\
\text { bij afwijkende MRI }\end{array}$ & $9 \%\left(11 / 120^{\mathrm{a}}\right)$ & $11 \%(21 / 180)$ \\
\hline \multicolumn{3}{|c|}{$\begin{array}{l}\text { DCE dynamic contrast enhanced, DWI diffusion weighted imaging, PrW Pros- } \\
\text { taatwijzer } \\
\text { aGeëxtrapoleerd ter correctie van non-compliantie voor het biopt } \\
\text { bVan het totaal aantal significante PCa's }\end{array}$} \\
\hline
\end{tabular}

bij alle patiënten, of wanneer bevindingen in de follow-up zouden zijn meegenomen.

2. De bioptcompliantie was niet perfect, waardoor terug moest worden geëxtrapoleerd naar de absolute aantallen wanneer $100 \%$ met een indicatie voor een biopt daadwerkelijk was gebiopteerd. Hierbij werd gerekend met de opbrengst van mannen die wél waren gebiopteerd. Dit kan een zekere bias introduceren, maar geeft waarschijnlijk een wat ongunstiger beeld dan in werkelijkheid, want de biopten werden met name afgenomen bij de patiënten met een wat hoger risicoprofiel.

3. Het cohort betreft alleen patiënten die via de huisarts zijn verwezen. De huidige resultaten kunnen daarom niet direct worden toegepast op patiënten die op een andere manier in het traject komen, bijvoorbeeld na analyse vanwege LUTS of na interne verwijzing.

4. De gerichte biopten werden volgens cognitieve fusie tussen MRI en TRUS afgenomen, freehand. In de FUTURE-trial is voor patiënten met een eerder negatief biopt aangetoond dat deze strategie vergelijkbare uitkomsten heeft als softwarefusie of MRI- in-bore prostaatbiopten, maar het betrof hier patiënten met een eerder negatief biopt [11].

5. Er werd biparametrische en niet multiparametrische MRI gebruikt, zoals door de PI-RADS-commissie wordt geadviseerd. De laatste jaren zijn er echter verschillende studies en meta-analyses verschenen die beide protocollen met elkaar hebben vergeleken en een vergelijkbare sensitiviteit en specificiteit melden voor de detectie van significant prostaatcarcinoom [18, 19]. De PI-RADS-commissie heeft dan ook recent in een officieel statement laten weten dat een bpMRI een acceptabele optie is bij bioptnaïeve patiënten [20].

6. De situatie waarin alleen gerichte biopten worden genomen, zal ook in de verdere behandeling op vele momenten impact hebben. Voorbeelden hiervan zijn de risico-inschatting voor active surveillance versus de indicatie voor actieve behandeling, follow-upbiopten tijdens active surveillance, risicoinschatting voor disseminatieonderzoek, planning van zenuwsparing tijdens prostatectomie, indicatie voor lymfeklierdissectie, etc.

7. Grotere aantallen patiënten zouden de huidige resultaten verder valideren, maar deze zijn min of meer in lijn met de literatuur.

\section{Verdere verfijning van het diagnostisch pad}

Er zijn vele opties denkbaar om de het diagnostisch pad verder te verfijnen.

- PI-RADS 3. Het initieel achterwege laten van biopten bij PI-RADS 3-laesies zou $11 \%$ van de bioptindicaties vermijden, $11 \%$ van de Gleason $3+3=6$ tumoren en $3 \%$ van de significante tumoren missen. Bij PI-RADS 3 én density $<0,15 \mathrm{ng} / \mathrm{ml} / \mathrm{ml}$ én een normaal rectaal toucher zouden deze getallen respectievelijk $6 \%, 3 \%$ en $0 \%$ zijn.

- Rectaal toucher. Van de 73 mannen met een afwijkend rectaal toucher, hadden er 13 (18\%) een normale MRI. Omgerekend hadden 3 patiënten Gleason $3+3=6$ en 3 patiënten significante kanker. Deze (kleine) groep wél biopteren levert $4 \%$ meer bioptindicaties op, $3 \%$ meer Gleason $3+3=6$ - en $3 \%$ meer significante tumoren.

- Preselectie voor MRI. In ons pad onderging iedereen een MRI. In Nederland wordt regelmatig de prostaatwijzer sequentieel met de MRI ingezet, dat wil zeggen dat er pas een MRI wordt verricht als de prostaatwijzer afwijkend. Dit lijkt logisch, maar de strategie wijkt af van de uitkomsten van de grote MRI-studies, zoals PROMIS en PRECISION [2, 6]. Reesink et al. lieten eerder zien dat, alhoewel er met deze strategie inderdaad op het aantal MRI-scans kan worden bespaard, significante tumoren kunnen worden gemist (bij afkappunt prostaatwijzer 20,0\%: $53 \%$ minder MRI's, maar $19 \%$ relatief gemiste significant prostaatcarcinoom; bij afkappunt prostaatwijzer 12,5\%: $31 \%$ minder MRI's, maar $7 \%$ 


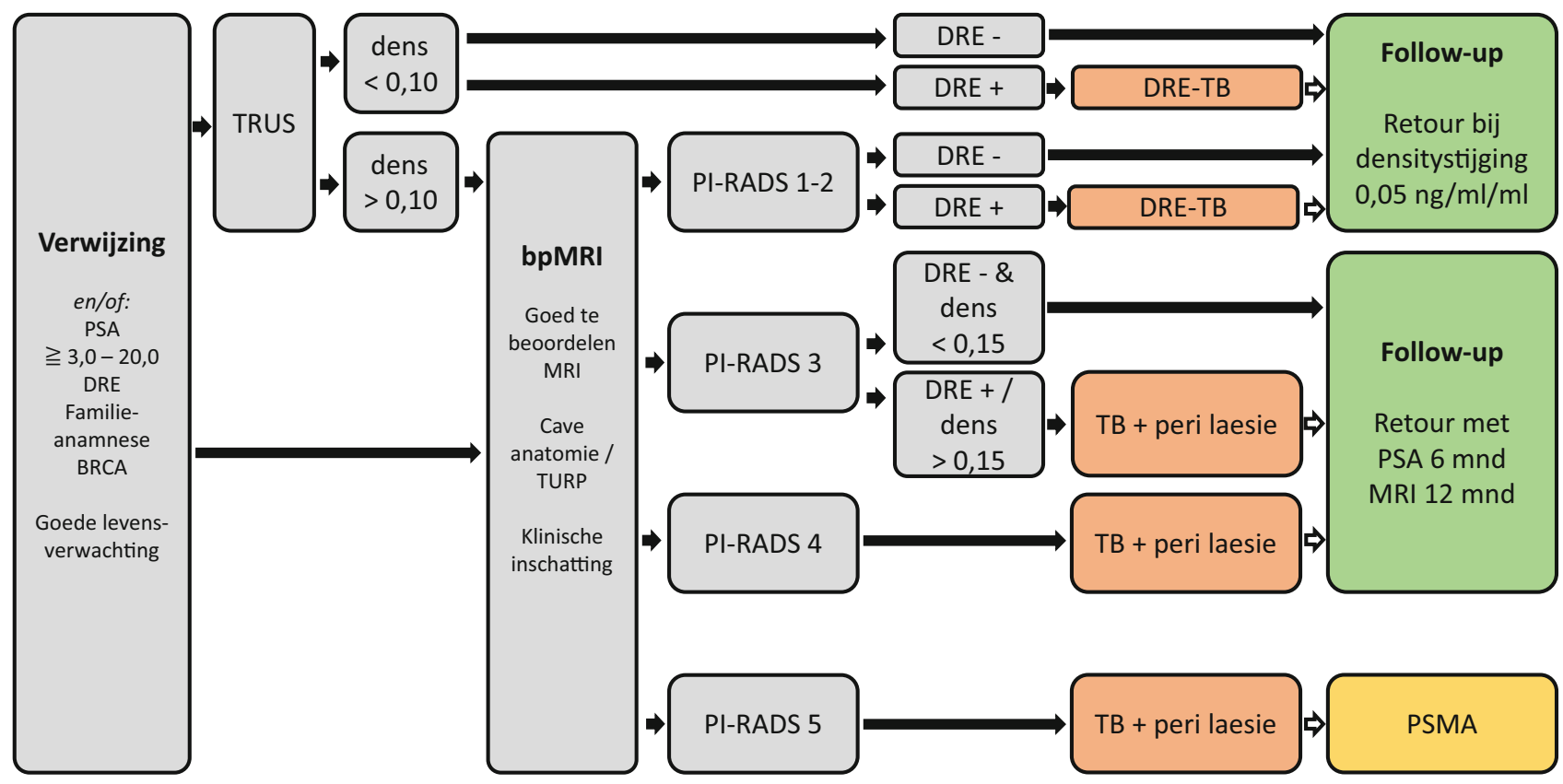

Figuur 2 Voorbeeld van een risico-gebaseerd, MRI-gericht protocol bij de verdenking op prostaatcarcinoom. Door de PSA-density (dens) te berekenen, kan een preselectie voor MRI worden gedaan. Een afwijkend rectaal toucher (DRE) blijft altijd een reden voor nader onderzoek. Alleen bij een afwijkende MRI is er een indicatie voor gerichte biopten (TB), die worden gecombineerd met biopten rondom de laesie.

relatief gemiste significant prostaatcarcinoom) [5]. Bij een pad met MRI als eerste stap worden minder significante tumoren gemist dan wanneer eerst de de prostaatwijzer wordt ingevuld. Figuur 2 presenteert een mogelijkheid voor een op risico gebaseerd MRI-pad.

Het diagnostisch pad voor de verdenking op prostaatcarcinoom bestaat tegenwoordig uit een keten van stappen waarin huisarts, uroloog, radioloog, nucleair geneeskundige en patholoog samenwerken. De indicatie voor en kwaliteit van iedere stap beïnvloeden het vervolg. Binnen bestaande richtlijnen zijn er per centrum of behandelaar natuurlijk specifieke keuzes te maken. Het is belangrijk om inzicht te hebben in de eigen resultaten, om te kunnen vergelijken, veranderen en verbeteren.

In dit kader is de Dutch Registry Of Prostate Pathway using Imaging and Targeted biopsy only ('DROPP-IT') gestart. Aangesloten centra zullen jaarlijks geanonimiseerd data delen en deze vergelijken op patiëntkarakteristieken, bioptindicaties, MRI-uitkomsten, manier van biopteren, pathologie-uitslagen en uitkomsten van follow-up. Door met andere centra te vergelijken, kan inzicht worden verkregen in de eigen kwaliteit, maar kunnen ook de resultaten van centrumspecifieke details en verfijningen van het protocol worden geëvalueerd.
Bij PI-RADS 3 is er een bioptindicatie bij een hoge PSA-density. Het kleine deel van mannen met een PI-RADS 5 laesie met negatieve biopten wordt door middel van PSMA (prostaatspecifiek membraanantigeen) gecontroleerd. Er wordt een standaard follow-up geadviseerd. bp biparametrisch, BRCA breast cancer gen, PSA prostaatspecifiek antigeen, TRUS transrectal ultrasound

\section{Conclusie}

Bij de verdenking op prostaatcarcinoom via de huisarts met laagdrempelig een MRI-scan resulteert:

1. het achterwege laten van systematische biopten bij een normale MRI, in een daling van het aantal biopt-

indicaties met bijna 1 op 3, met als gevolg dat $7 \%$ van de significante tumoren wordt gemist;

2. het achterwege laten van systematische biopten bij een afwijkende MRI en vertrouwen op gerichte biopten alleen, resulteert in een daling van ongeveer $75 \%$ van de bioptcores per onderzoek, met als gevolg dat $9 \%$ van de significante tumoren wordt gemist.

Met inzicht in de eigen resultaten en prospectieve registratie, kunnen deze bevindingen worden gebruikt om te komen tot verdere verbetering van het diagnostisch pad voor patiënten met de verdenking prostaatkanker.

\section{Patiëntensamenvatting}

Door bij patiënten met de verdenking op prostaatkanker volledig af te gaan op de MRI-scan en ook alleen gerichte biopten te nemen, wordt een beperkt percentage belangrijke vormen van prostaatkanker gemist. Aan de andere kant daalt het aantal mannen bij wie het onderzoek nodig is en het aantal biopten 
dat wordt afgenomen. Vaste controlemomenten kunnen dit eventueel ondervangen. Goed inzicht in eigen patiëntenstromen, MRI- en bioptresultaten zijn een voorwaarde voor veranderingen binnen het protocol.

Open Access This article is distributed under the terms of the Creative Commons Attribution 4.0 International License (http://creativecommons.org/licenses/by/4.0/), which permits unrestricted use, distribution, and reproduction in any medium, provided you give appropriate credit to the original author(s) and the source, provide a link to the Creative Commons license, and indicate if changes were made.

\section{Literatuur}

1. Mottet N, Bergh RCN van den, Briers E, et al. EAU-EANMESTRO-ESUR-SIOG guidelines on prostate cancer-2020 update. Part 1: screening, diagnosis, and local treatment with curative intent. Eur Urol. 2021;79(2):243-62.

2. Kasivisvanathan V, Rannikko AS, Borghi M, et al. MRItargeted or standard biopsy for prostate-cancer diagnosis. NEnglJ Med. 2018;378(19):1767-77.

3. Sathianathen NJ, Omer A, Harriss E, et al. Negative predictive value of multiparametric magnetic resonance imaging in the detection of clinically significant prostate cancer in the prostate imaging reporting and data system era: a systematic review and meta-analysis. Eur Urol. 2020;78(3):402-14

4. Roobol MJ, Verbeek JFM, Kwast T van der, et al. Improving the Rotterdam European randomized study of screening for prostate cancer risk calculator for initial prostate biopsy by incorporating the 2014 International Society of Urological pathology Gleason grading and cribriform growth. Eur Urol. 2017;72(1):45-51.

5. Reesink DJ, Schilham MGM, Hoeven EJRJ van der, et al. Comparison ofrisk-calculator and MRIand consecutivepathways as upfront stratification for prostate biopsy. World J Urol. 2020; https://doi.org/10.1007/s00345-020-03488-2.

6. Ahmed HU, El-Shater Bosaily A, Brown LC, et al. Diagnostic accuracy of multi-parametric MRI and TRUS biopsy in prostatecancer(PROMIS): a pairedvalidating confirmatory study. Lancet. 2017;389(10071):815-22.

7. Ploussard G, Borgmann H, Briganti A, et al. Positive prebiopsy MRI: are systematic biopsies still useful in addition to targeted biopsies? World J Urol. 2019;37(2):243-51.

8. Ahdoot M, Wilbur AR, Reese SE, et al. MRI-targeted, systematic, and combined biopsy for prostate cancer diagnosis. NEngl J Med. 2020;382(10):917-28.

9. Ahdoot M, Lebastchi AH, Long L, et al. Using Prostate Imaging-Reporting and Data System (PI-RADS) scores to select an optimal prostate biopsy method: a secondary analysis of the Trio study. Eur Urol Oncol. 2021; https:// doi. org/10.1016/j.euo.2021.03.004.

10. Leest $\mathrm{M}$ van der, Cornel $\mathrm{E}$, Israël $\mathrm{B}$, et al. Biopsy in biopsy-naïve men with elevated prostate-specific antigen: a large prospective multicenter clinical study. Eur Urol. 2019;75(4):570-8.
11. Wegelin O, Exterkate L, Leest M van der, et al. The FUTURE trial: a multicenter randomised controlled trial on target biopsy techniques based on magnetic resonance imaging in the diagnosis of prostate cancer in patients with prior negative biopsies. Eur Urol. 2019;75(4):582-90.

12. Epstein JI, Amin MB, Reuter VE, et al. Contemporary Gleason grading of prostatic carcinoma: an update with discussion on practical issues to implement the 2014 International Society of Urological Pathology (ISUP) Consensus Conference on Gleason grading of prostatic carcinoma. Am J Surg Pathol. 2017;41(4):el-e7.

13. Roobol MJ, Schröder FH, Hugosson J, et al. Importance of prostate volume in the European Randomised Study of Screening for Prostate Cancer (ERSPC) risk calculators: results from the prostate biopsy collaborative group. World J Urol. 2012;30(2):149-55.

14. Barentsz JO, Weinreb JC, Verma S, et al. Synopsis of the PIRADS v2 guidelines for multiparametric prostate magnetic resonance imaging and recommendations for use. Eur Urol. 2016;69(1):41-9.

15. Bergh RCvan den, Albertsen PC, BangmaCH, etal. Timing of curative treatment for prostate cancer: a systematic review. Eur Urol. 2013;64(2):204-15.

16. Stavrinides V, Giganti F, Trock B, et al. Five-year outcomes of magnetic resonance imaging-based active surveillance for prostate cancer: a large cohort study. Eur Urol. 2020;78(3):443-51.

17. Ghani KR, Dundas D, Patel U. Bleeding after transrectal ultrasonography-guided prostate biopsy: a study of 7-day morbidity after a six-, eight- and 12-core biopsy protocol. BJUInt. 2004;94(7):1014-20.

18. Kuhl CK, Bruhn R, Krämer N, et al. Abbreviated biparametric prostate MR imaging in men with elevated prostatespecific antigen. Radiology. 2017;285(2):493-505.

19. Kang Z, Min X, Weinreb J, et al. Abbreviated biparametric versus standard multiparametric mri for diagnosis of prostate cancer: a systematic review and meta-analysis. AJR Am J Roentgenol. 2019;212(2):357-65.

20. Schoots IG, BarentszJO, BittencourtLK, etal. PI-RADScommittee position on MRI without contrast medium in biopsynaivemen with suspected prostatecancer: narrative review. AJRAm J Roentgenol. 2021;216(1):3-19.

dr. Roderick C.N. van den Bergh, uroloog

drs. Daan J. Reesink, uroloog

drs. Lieke Wever, uroloog

drs. Timo F.W. Soeterik, uroloog

drs. Sandrine van Selm, uroloog

drs. Pascal E.F. Stijns, uroloog

dr. Erik J.R.J. van der Hoeven, radioloog

dr. Peter C. de Bruin, patholoog

dr. Harm H.E. van Melick, uroloog 